\title{
Distinctions of Authenticity and the everyday punk self
}

\author{
Alastair Gordon, Leicester De Montfort University
}

\begin{abstract}
This article examines the construction authenticity of a particular UK DiY punk scene. Using ethnographic data gathered in 2001, it examines members' reference to broader ethical ideological themes through an analysis of their interviews. I offer the model 'Distinctions of Authenticity', which identifies four key component strategies at work in the pursuit of selfauthentication that have purchase for future work on punk authenticity studies. This model challenges reductionism models of a singular punk authenticity. In doing so it presents an approach to overcome what are identified as key gaps in subcultural research left by both traditional (BCCCS) subcultural research and later post-structuralist accounts that do not fully take into account the workings of micro-discourse in maintaining and constructing subcultural punk authenticity.
\end{abstract}

\section{Keywords}

authenticity

punk

DiY

CCCS

subculture

post-subculture 
genre

ethnography

To find an authentic punk one only has to listen to their contextual talk for that is where it exists and is endlessly reconstructed.

In the 1970s youth subcultural research output from the Birmingham Centre for Contemporary Cultural Studies (hereafter CCCS) contained an ideological gloss. It overlooked examination of the ways in which mutual discussion between subculturalists served as a sequential vehicle for positive and negative authentication between members within a subculture. Broadly the CCCS offered a model of subcultures as coherent blocs, doing sartorial battle with other subcultures or trying to weed out inauthentic 'poseurs' through predictable disciplinary channels of commodification and ideological control (Cohen 1972; Hebdige 1979). The CCCS' explanatory value lay in its account of subcultures collectively operating reflexively through the 'problem solving' approach between social structures (class, race, gender and family), hegemony and subculturalist agency. Subcultural attempts at problem solving were transposed into sartorial expression and collective, rebellious exhibitions to voice youth identity. The constructivist elements of subcultural authentication remained absent in the CCCS canon and beyond until the early 1990s, although subsequent developments led the way to the present research. That is not to say that gaps in subcultural groups were completely lost upon the CCCS. In a rather telling passage, Clarke et al. noted,

[Subcultures] win space for the young: cultural space in the neighbourhood and institutions, real time for leisure and recreation, 
actual 'territory' in the locality. They focus around key occasions of social interaction: the weekend, the disco, the bank-holiday trip, the night out in the centre, the 'standing about doing nothing' of the weekday evening, the Saturday match. They cluster around particular locations. They develop specific rhythms of interchange, structured relations between younger to older, experienced to novice, stylish to square. They explore 'focal concerns' central to the inner life of the group: things always 'done' or 'never done', a set of social rituals which underpin their collective identity and define them as a group instead of a mere collection of individuals ([1970] 1989: 64 in Bennett et al. 1989, emphasis added).

This passage encompasses three themes of concern to the present discussion. First, while overlooking the various, competing ages of subcultures, the authors illuminated the CCCS tendency to present subcultures as uniform blocs that demarcate authenticity between each other and not within each group: 'stylish to square'. Second, they revealed a political/ethical antagonism over youth identity regarding contestation of public space for subcultural activity. Third, and most importantly, they signposted the value of discourse between and within youth culture by importantly noting the 'rhythms of interchange'. These 'rhythms' are of particular relevance in the following discussion, especially when they contest and evoke authentic discourse within a subculture. The CCCS were certainly correct in identifying the minutia of subcultural talk, although it would be at least two decades before these exact rhythms of subcultures were identified in detail (see Widdicombe and Woofit 1995).

The CCCS theoretical oversight was addressed via the post-subcultural literature (see, though not exclusively, Straw 1991; Thornton 1995; Muggleton 1999; Muggleton and Weinzierl 
2003; Hodkinson 2002; Bennett 2006). It operated under the broad banner of postmodernism/post-structuralism, deploying explanatory frameworks hostile to reductionism and truth seeking, and instead adopting methodological approaches sensitive to the microdetail and linguistic explorations of authenticity. This revisionist corpus of research offered an overarching critique of the CCCS and revisited existing participants' 'postmodern' subcultures to examine competing insider claims of everyday subcultural practice. It gathered data through ethnographic interviews and participant observation methods. The general motif of this later work fractured CCCS tropes presenting subcultures as unified blocs - for example, Mods and Punks as the preserve of 'youth'. Instead it presented detailed accounts of subcultural practice (see Bennett \& Peterson 2004, Bennett and Hodkinson 2012). However, the general critique of this work lies in their restricted debates of the construction of sartorial style through authenticity. This is a general problem running through both sets of research. The construction of ethically informed authenticity is absent.

\section{The cul-de-sac of punk talk, trousers and missing ideologies}

The purpose of this article asserts that CCCS and post-subcultural literature do not represent 'breaks' in the study of subcultures per se and instead offers a coherent shift from macro- to micro-methodological and theoretical approaches. What is required to address this omission is to amalgamate the two approaches to take account of macro and micro subcultural perspectives - for example, to examine how subculturalists deploy and construct ethics and authenticity within and across age and peer groupings.

Widdicombe and Woofitt's (1995) The Language of Youth Subcultures whilst predating the post-subcultural literature is of value to what follows as it specifically deploys conversation analysis as a micro-approach to authenticity in subcultural life (Sacks 1995; Antaki 2000). 
Deploying conversation analysis offered an account of how youth subcultures are sequentially constructed via everyday talk, which orients speaker utterance through 'membership categories' to 'do' the language business of authenticity in daily subcultural life. Such research was not without problems, as the method clearly glossed over wider ideological and macro-contextual frames choosing to instead focus on conversational pauses and micro-interactions and 'identity work' of the subculturalists. Contextual issues of social structures inflecting this talk were avoided, although their approach clearly signalled the value of everyday subcultural conversation. Again though, the prefix on sartorial style overshadowed general, wider structures that both shaped and produced subcultural conversation.

Muggleton's (1999) subsequent post-subcultural discussion of how group resistance to parental authority signalled a welcome reintroduction of theoretical accounts of ideological structures to for the present debate. Indeed the CCCS argument is a convincing one, illustrating how parenting is informed by overarching social, traditional and cultural structures of hegemonic authority. Yet, Muggleton overlooked how and in what ways these structures informed subcultural practice; the analysis is passé. Significant detailed examination from Muggleton of why the role of anarchism or vegetarianism cited by his interviewees as an ideological counter-cultural discourse and site of tension within punk was not examined: instead, clothes were deemed a more suitable locus of discussion. Hence, crucial questions of context and contested subcultural structures of authenticity/ethical practices informed by ideological structure - in the CCCS sense - were overlooked: detail is presented in Muggleton's work; yet the ideological and ethical context is again eclipsed. The key cites of present interest - namely, authenticity and ethics - are not sufficiently addressed.

The absence of such key areas of focus appears rather odd. Indeed, ethical, moral and authentic discourses are legion in punk (see Gordon 2015). These serve to both authenticate 
and discipline scene members navigating a tacit web of nebulous codes of authentic conduct and ethical rules. In CCCS approaches and also in the work broadly detailed as Critical Discourse Analysis (Fairclough 1989) ideological structures play a central role in an analysis of discourse. Such approaches prove useful as a methodological influence on the model to be introduced below. The connection of spoken discourse, gesture and style with overarching ideological systems of power completes the theoretical gap thus far. For example, in anarcho punk, the counter-cultural legacy of anarchism, vegetarianism, the DiY ethic and direct political action became part of the general structural locus that certain subsections of punks reflexively proclaimed and defined as their authenticity. It was equally informed by what it proclaimed not to be. For anarcho punk constructs some - though not all - of its praxis by resisting sexist, right wing, capitalist social structures, shunning those punks who engage with major record labels. In what follows there is intrinsic value in addressing the gap via production of a general theory focusing principally on how individuals construct their ethical and authentic action through language reciprocally informed, framed and shaped through general social, cultural and ideological power structures.

By drawing generally on the approach of Critical Discourse Analysis and Grounded Theory, relative general structures of convention (ethics, authenticity and conduct) informing punk's authentic practice can be identified (Glaser and Strauss 1967; Strauss and Corbin 1990). Such structures are evident in interviews presented later in this article. A total of 40 self-identified punks aged 19-47 years (anonymized for this article) were interviewed in Leeds and Bradford whilst participant observation research was undertaken in Bradford in 2001. My interest was not about discovering a universal, defining authentic punk practice per se but instead to examine how and in what ways punks constructed themselves as authentic in relation to their personal, historical, ideological, social and cultural context. This was achieved by identifying key aspects of participant interview discourse that both constructed 
and reflected intrinsic conventional subcultural structures of authenticity, ethics, selling out and markers of difference. The most important point of departure, however, to both of these approaches was to explicitly avoid discussion of clothing style in any depth.

My role at the time of the research as an active participant in the UK DiY punk scene informed the fieldwork journal data in tandem with incorporation of autodidactic DiY punk literature. My role in the present article is one of both author and self-identified punk, one familiar with the issues raised by interviewees. This role functions both as an analytic tool and also as an individual familiar with punk accounts of ethics and authenticity. Analysis of the data was undertaken using the aforementioned Grounded Theory in order to incorporate my role as a participant in what follows (Glaser and Strauss 1967; Glaser 1978, 1992; Strauss and Corbin 1990). The data analysis revealed a general, transpositional framework offering a theory of how members of the UK DiY punk culture contextually authenticated themselves. This occurred along four, key provisional discursive components. This model is named 'Distinctions of Authenticity'.

\section{Distinctions of Authenticity}

Participation in the punk scene always involves trading in discourse and gestures of authenticity, which both sustain existing ethical and authentic subcultural structures and simultaneously reproduce, revise and (re)construct such issues. For example, proclaiming a ment [S1]: Please verify the accuracy of the changes made to the sentence. punk subcultural peer a 'sell-out' or poseur for, say, purchasing a punk band's music on a major label while simultaneously proclaiming a militant DIY status transgresses an implicit ethical code of remaining authentic to an original punk folklore of doing it yourself. The wider notions and legacies of this ethical (DiY) position of authenticity stem from the first wave of punk, yet have historically morphed and extended into new (often constraining) ethical forms as wider subcultural structures informing practice change. Such changes are reproduced, constructed and adapted through punk subcultural discourse. Similar examples 
include punks demonstrating experience and practice of punk culture, trading knowledge of musical canon and generally/reciprocally identifying instances of inauthentic punk practice. Distinctions of Authenticity hitherto attempts to map these constructs, offering a reflexive model for studying this practice.

This model clearly takes influence from previous theoretical accounts such as Thornton's (1995) 'subcultural capital' or 'hipness'. However, Thornton's model of subcultural capital revealed little of how participants amassed such 'capital' prior to full engagement within the subculture or how they became adept in their use (1995: 11, see also Gordon 2015). Equally, the problem with subcultural capital is that it is economic in reference and has little to say either about how it operates discursively in the production of subcultural authenticity within subcultural structures, or how discussion of key subcultural structures locates some participants as inauthentic or ethically dubious. It is equally problematic in terms of its use of the descriptor 'subculture' as opposed to scene, yet the former term will be innocently deployed here in the interests of conceptual narrative and continuity. This is not to be naive to the general confusion this term presents in terms of comparison to other descriptors such as scene, community and field (see Straw 1991; O’Connor 2002a, 2002b, 2003, 2008).

The model of 'Distinctions of Authenticity' has specific meaning with regard to the punk subculture and serves a plurality of functions in relation to the construction of scene authenticity within the construction and engagement with the construction of, and location within, a range of authentic and ethical subcultural conventions informed by wider social structures. What follows are both indicators of how subculturalists negotiate these structures as measures of identification and a demarcation against what is deemed to be subculturally inauthentic (the poseur in the classic CCCS sense of the term). The adept and careful use of this model 'Distinctions of Authenticity' reveals how peer acceptance of the participant is 
played out within and beyond punk culture allowing them to construct in context the authentic (or inauthentic) discourse of punk rock.

Repeated engagement with debates around authenticity transposes into authentic conduct. Subculturalists gradually learn and cultivate knowledge through trial and error (see Gordon 2014). The subsequent punk subculture member has at his or her disposal knowledge of previous scene experiences (operating within wider subcultural conventions, ethical or otherwise) that permit them to conduct reciprocal authentic activities and to simultaneously distinguish/construct themselves from inauthentic conduct. Authenticity is therefore central to the subsequent actions and conduct within subcultural groupings if one is to be accepted into them by peers. Distinctions of Authenticity reveals a set of clear yet overlapping subcultural norms and values central to DiY punk that, on the one hand, views inauthentic action both with suspicion, scorn, jealousy and fear and, on the other, hails authentic action with awe, respect and subcultural honour. However, the reverse of the previous statement is also applicable here in that overly authentic subcultural practice - 'trying too hard' as Thornton (1995 astutely noted - may generate similar results. Through a detailed examination of Distinctions of Authenticity, such processes are rendered visible on four non-mutually exclusion intersections discussed below.

Echoing the classic CCCS research (Hebdige 1979) yet developing this beyond the macroperspective, authentic practice, those activities that reciprocally operate in tandem with the ethical frameworks of punk, can be used at a number of reciprocal levels - for example, discursive and extra-discursive - to simultaneously 'interpolate and hail' (to borrow from Althusser [1970]) the subcultural practitioner as a bona fide, authentic member and reciprocal members as either inauthentic impostors, 'poseurs' or outsider group members inhabiting a peripheral, insignificant or uninterested subculture through their 'lack' of command or expertise in their use of subcultural conventions. 
What I am suggesting thus far relates to the idea of amassing what can be considered Distinctions of Authenticity within a provisional number of levels. The rhetorical evocation of subcultural knowledge conventions is of central importance here: for example, discussion and citation of bands considered to be part of a punk canon (Jenkins 1992; Shuker 2011; Ville Karja 2006), the correct perceived and enacted ethical conduct, issues of gender and race, places, people, records, venues, fanzines, record labels and records and CDs, and almost any facet of subcultural punk activity and knowledge is applicable to this model. The list is contextually endless and historically relative - collected through participation and understanding of subcultural conventions within the punk subculture. This has a potential, rhetorical purpose to it. When used in the service of a subculturalist's reflexive credibility, such knowledge can be used both as a contestation of authenticity and also as a marker of the subject's inauthentic peer status.

As most of the interviews retrospectively examined participants' subcultural entrance, involvement and exit regarding most of the genres involved in punk could be easily quoted from a 'knowing subject' ethical subcultural position. Such usage is not innocent in all cases and in many respects serves a clear rhetorical purpose. Genre and punk music canon usage (deployment of key band names, places, key figures and times, examples of 'fake' punk, etc.) and the demonstration of this knowledge are central in the construction of that subject as an authentic member and participant of the subculture. Such devices are used to perform and contest simultaneously pejorative put-downs in the defence, production and bolstering of one's own authentic subcultural practice or, instead, to defend the subject's own version of authentic subcultural practice. Thus, this presents the question 'How are Distinctions of Authenticity deployed in the construction, defence and identity of the practitioner punk culture?' Punk authenticity is established through action, awareness of key knowledge and dialogue. 
Distinctions of Authenticity demonstrates the long-standing continuity of the punk subculture in eternal flux, thus thwarting elitist attempts to place endpoints upon punk while also historically locating some of the contestation regarding the authenticity of competing genres and their contribution to authentic punk practice. I note that this section is by no means a comprehensive overview of all punk genres over the past 30 odd years (thus ironically placing myself as the authentic author of a fully informed and 'all-knowing' historical document!). I focus only on the claims made in the interviews, field notes and my own punk subculture membership regarding the initial influence that certain punk events, music and activities had on the interviewees in their specific forms of subcultural practice. Such claims both reflect and reconstruct wider, more prevalent ideological punk subculture tropes (e.g., DiY and selling out).

What follows is an account of how these interrelated sections of discourse are played out in the interviewees' statements of entrance into and early experience of punk culture. I take care to note here that these are not mutually exclusive, partitioned 'common places' (Billig, 1992: 17) of discourse and instead mutually contest and inhabit each other. This model contains four non-mutually exclusive areas of interview data where authenticity is contested. These are the authentic original, membership badges, genre location indicators, and the hated yet related.

\section{The authentic original}

'Back in the day' was/is a common everyday term used by punks to construct a perceived 'golden age' of subcultural activity. One of the most common examples of this in macropunk discourse is for participants to refer to a subjectively considered 'classic' period of punk rock in the 1970s and the associated debates between United States and United Kingdom versions of punk rock or some important subcultural 'heyday', specific to the participant's experience, involvement and historical, geographical and cultural location. 
The authentic original relates to musical genres and activities used by informants to rhetorically define and contest what is/is not deemed to be punk rock. This operates across geographical, ethical and historical timelines. When Martin talks below of the 'pointless wanking' of progressive rock, he sets up punk as an authentic alternative musical discourse, simultaneously offsetting other, previous genres as inferior, elitist or substandard in contrast to the 'honesty' of the punk aesthetic. This method of rhetorically 'putting down' past, present and future musical genres of punk (and other musical genres) is a method of constructing the speaker's authentic version of punk within wider structural conventions of authenticity. The most common form of such convention is related either to the origins of punk rock or to the 'classic' period of punk existing from 1976 to 1979.

A way in which authenticity in music is defined is by the rhetorical marking out of a particular genre in contrast to others, which are deemed superficial, pretentious or sham. This strategy is evidenced in the contradistinction of punk and progressive rock illustrated by Martin:

\footnotetext{
During the seventies when I was kind of a young, middle teenager my peer group were all into this kind of Genesis and Yes [music] and I kind of knew it was wrong but I couldn't put my finger on what it was. It seemed like you had to pretend you liked it even though you didn't. And I didn't really like it, I mean both of those bands have the odd good tune but there is really an enormous amount of pointless wanking.
}

Here, the first claim of knowing there was something wrong with the music is invoked against the tastes of Martin. 'Pointless wanking' is a pejorative, descriptively inflated put- 
down that both articulates Martin's unease with the exclusivity of leading music genres in the mid-1970s and prepares the ground for his own identification with the inclusivity of punk, which is then set up in opposition to what is commonly regarded in punk as a self-indulgent, even shameful, activity. No one, except possibly the most abject masochist, wants to be defined as, or associated with, 'pointless wankers'.

Paradoxically, though, this is a sharp boundary demarcation that runs against the notion of punk culture as inclusive since it requires that 'authentic' music be performatively dissociated from what is construed as 'inauthentic' (pop, progressive rock, or whatever). Martin stated that when Peel first played the Ramones in 1976 against the backdrop of the progressive rock of the time, he thought it was a joke, yet a hugely influential one:

I thought it was a joke and then I realised that it wasn't. I worked out that it was full of energy. You can name this record to your mate and say, 'here, listen to this it's exciting straightforward and direct'. Previously my friends would lend me records and they would be saying 'listen to this' if you don't like it means that I am cleverer than you which wasn't a deal that I wanted to be in. So [I heard] the Damned, The Ramones like millions of other people the music they heard on John Peel got me involved in punk. (emphasis added)

Here the specific tool for identifying the construction of authenticity is Martin's oppositional self/other depiction of early punk music as initially 'a joke' before recognition of its authenticity (against the implied alienating and exclusive properties of progressive rock). Such recognition is implied within the claims that such music is 'straightforward and direct', exemplifying how musical appreciation is carried out and interpreted. The reference here is 
not so much to the 'pointless wanking' of progressive rock (though he does refer to statusseeking) as it is to the rhetorical construction of early punk's structural musical convention of simplicity; yet the result is the same. What is set up is an authentic original marker of distinction against progressive rock and the perceived aesthetic elitism Martin identified with it. The moral compass points at progressive rock as inauthentic.

Early divisions were evident over peer interpretations of American and English punk genres, and this reflected divisions between the United Kingdom and United States in the late 1970s. As another interviewee, Dave, made clear, such divisions could have alarming consequences when the moral compass of inauthenticity was aimed at him:

My local like Sid Vicious character kind of guy modeled himself on Sid or whatever. I used to think of myself as a bit of a Johnny Ramone you know. I had kind of like long hair. This guy came up to me and he's like wiggling going 'the hippy, hippy shake!' This was on Armstrong Bridge in Newcastle and it's a hundred foot drop and he cornered me with his mates 'cause my mates got away, and he's like giving me shit for being a hippie, which is ridiculous as I had a Ramones shirt on. The guy didn't get it you know. My Chopper [bike] was thrown over and they had basically picked me up and were threatening to throw me off this bridge. They could have fucking killed me and I was terrified.

The above division is made clear from Dave's testimony through his discrimination between 'punks at the time who got it and punks who didn't'. Here the claims of being into the Ramones can be identified in structural convention terms as 'authentic original' statements of Distinctions of Authenticity. The Sid Vicious 'look-alike' in this example is constructed 
through his identification with the 'second hand' look of UK punk and also captured in his misrecognition of what Dave refers to as the authentic original punk look with what he and the band considered central in the formation of the punk genre. Those who did not 'get this' were hailed by Dave as inauthentic, and indexical to their subcultural ignorance was the potential for misconstrued practice. However, what this quotation equally offers is an example of the extra-discursive business that visual subcultural symbols play. Here, Dave's quotation highlights that an authentic member of the subculture - one who applies Distinctions of Authenticity correctly - would avoid inauthentic action such as misreading haircuts and t-shirts and 'hippyness' when they are allegories of an authentic deployment of correctly understanding US punk conventions. Admittedly, style raises its ugly head here, although when combined with the action and practice of those concerned the value of the sartorial style both connects and constructs authenticity. For example, however terrifying, Dave's assailants were punk parochials. Their transatlantic illiteracy substantially diminished their subcultural status as genuine participants in punk.

What is clear from the above examples is how the category of 'authentic original' operates through the award of authentic subcultural credentials to the speaker whilst simultaneously 'othering' inauthentic genres/participants, whose reciprocal understanding of 'early genres of punk' (Ramones) were initially understood and presented as misguided. Through such devices the subcultural past of the speaker is authentically proclaimed. The authentic original can be used to authenticate the speaker through their association/first-hand experience and long-standing knowledge of subcultural macro-conventions; it can educate and inform a potentially subculturally inexperienced listener, produce envy, admiration and a plethora of mixed emotional responses/reactions from the listener, and finally serve as a marker of the length of subcultural experience a participant has gained that is not specifically restricted to 
the boundaries of the subculture. The business of punk authenticity works between both the macro and micro levels of analysis.

\section{Membership badges}

These are the historically and culturally relevant, visible and spoken categories and discourses of macro- and micro-punk conventions. Typically interviewees used such terms to place themselves at, or demonstrate knowledge of, key historical subcultural intersections of perceived authenticity, thus potentially asserting themselves or contesting others as authentic/inauthentic subjects. The 'authentic original' category involved mentioning contextually salient band names, records, concerts, places and most importantly rhetorical discourses associated with punk convention. Within this category the interviewees were able simultaneously to identify a specifically located punk practice couched in cultural, social and historical space, yet also demonstrate the extent of their knowledge of the subgenres and scenes of punk. In comparison, membership badges are both synchronic and diachronic. For example, the older interviewees mentioned the 'classic' punk bands of the 1977-1979 period. Later bands were associated with different genres of punk that derive from the international interpretations of either the American, English (as demonstrated by Dave in the previous example) or European/US punk styles, such as hardcore and straight-edge (see Glasper 2009; Blush 2010; Haenfler 2007). In addition to this, the use of membership badges acts as a demonstration of 'insider' knowledge of both past and present subcultural activities. By mentioning specific genres within the interview setting and from my ethnographic field data/insider familiarity, the confirmation of one's knowledge of macro-punk cultural conventions and status as a scene member is either confirmed or at stake. 
Dave: this was like 84 so it was like Antisect, Dirt and Crucifix [on tour in the UK]. Antisect and Dirt, you know are pretty good, of course but Crucifix [from the US], they moved, they ran around, they brought it to life in a lot of ways and showed us British people. And this was after the whole summer of 84 thing. You have gotta look at it like. You have gotta put it in context with like the miners strike which I think was a massive a massive thing from pacifism into fucking realising that with stuff like Oregreave and just realising that it ain't gonna fucking work the way it's been before. Everything, miners strike and the way that Thatcher fucking tried or near enough, or broke the back you know of the unions and I think that that whole. I have gotta get that into context, I'm talking about bands and stuff, but back in like hardcore and stuff, Crucifix blowing us away and the likes of and that. And like you had at the end of 84 you had Dig going round selling $M R R$ with his fucking tatty looking pants or whatever.

Here, the historical and ideological structures are clear. Via the 'summer of ' 84 ' membership badge, Dave situated the ideological context of Thatcherism to punk, The Stop the City Protests, Miners Strike and the decline of anarcho punk within the geopolitical cold war context and how it both informed and shaped later developments in punk. These issues later transposed into the ways bands moved onstage, the speed and aggression of the music they played and the early inclusion of American Hardcore Punk into elements of UK punk. Yet, he also noted the transnational connections between the UK anarcho punk scene and the San Francisco band Crucifix. Dave constructs here what he considers a key intersection of UK to US punk that shaped what were for him subsequent developments in 1980s' punk. Citing the band names served to authenticate Dave's scene knowledge - he is explicitly aware of the marked differences that would be later synthesized for him in UK punk. These terms have a 
membership value requiring a level of scene knowledge that ultimately converts into authenticity within the subculture.

Indeed, the closing of the quote alludes to his early knowledge of the, then, new US punk fanzine, Maximum Rock and Roll, sold by Digby Pearson, later founder of the internationally famous and long-standing Nottingham hardcore punk label, Earache Records. I noted above that a central component of the present research was also my auto-ethnographic insider status. This is acutely evident here: my first-hand knowledge of events cited in Dave's quotation serve to reciprocally authenticate his testimony and equally validate the membership badges cited. A stark example of how membership badges are deployed to inauthenticate became evident when discussing the Crucifix shows with the interviewee. I was unable to attend the Crucifix show in Nottingham and was repeatedly reminded by the interviewee that missing this tour was to be absent from a key moment in UK anarcho punk history. Being frequently, yet humorously, chastised for not being able to attend this show - inferring an implied inauthenticity -equally marks the interviewee out as authentic through the good fortune of witnessing these shows.

\section{Genre location indicators}

In similar ways to membership badges, genre location indicators place the interviewee's authenticity within a specific geographical, cultural and historical juncture in punk culture. Such indicators include visible and spoken references to bands/members, records, labels, venues, fanzines concerts, social events and key figures within a specific subculture. Such indicators are made explicit in the previous category; yet the geographical and historical aspects serve to authenticate the speaker at different levels and locate them at a point in time and location within the punk subculture. Indeed, the use of such terms is complex since it can either represent an innocent recollection of a time and a scene and the potential sharing of newly discovered bands, records, labels, websites, concert dates, etc., or an elitist signal of 
cultural knowledge used to demonstrate evidence of authentic participation of the punk genre, rhetorically setting aside or displacing the speaker from those who are deemed 'inauthentic' or ill-informed members of the culture. Nicky mentioned the 1987 Radio One John Peel Sessions as influencing his subcultural development. This surfaces repeatedly as a mainline media support of DiY punk culture.

At that time you had John Peel doing the Radio One Show and he was putting out Peel sessions with like Heresy, The Stupids and Napalm Death and so you know it was like an early building block sort of state.

Here the specific knowledge of John Peel's sessions is invoked in addition to some of the key bands mentioned during that time. The dual purpose of this statement first locates the speaker as having the specific subcultural knowledge of the period of hardcore punk popularized by John Peel in 1987 as 'britcore' (see Glasper 2009). Second, use of the phrase 'early building block sort of state' locates the speaker in the subcultural present, demonstrating the appropriation of sufficient subcultural historical knowledge to show they understand the previous genre's roles in the construction of the present.

However, the previous quote fails to demonstrate the use of spatial and geographical genre location indicators within a specific scene. In what follows, the interviewee, Neil, uses subcultural colloquialisms as geographical markers in the Leeds/Bradford hardcore and punk scenes of the 1990s.

basically with a question about the 1 in 12 is like facing me with like a question about Leeds 6 basically, cause it's been there for years, it's like I was going to 
1 in12 gigs before the Club building existed for fucks sake! Erm, I guess I'm a circumstance of geography really because I was born and brought up within [a] close proximity of Leeds and Bradford.

Here the speaker navigates between innocent location indicators specific to the Leeds subcultural scene by using Leeds 6 (the Leeds postcode where key members of the Cops and Robbers music collective resided) as a point of geographical location and pejorative 'authentic original' statements through the claim that he attended the 1 in 12 club gigs before they obtained a grant for their own building. The innocent term Leeds 6 could be read as a straightforward geographical reference, but the interviewee is using the term as a mutual subculture location point with myself as the 'knowing' interviewer. In this instance, Leeds 6 has an invested subcultural knowledge and value in that if offers predominantly (but not totally) the potentially informative location of the majority of participants in the DiY scene of that area. Replete with such knowledge, the speaker is able to demonstrate sufficient knowledge as to render them an authentic scene member to other participants. This point has equal value for the sharing of subcultural scene knowledge. When involved in a subcultural investigation of knowledge of subcultural genres, geographical locations are both subculturally contested and discussed between members and shared though heuristic investigation.

\section{The hated yet related}

This category refers to unacceptable subcultural genres, some of which were cited as key influences on the interviewee's entrance to the subculture. Unacceptable (hated) genres are legion within the discourse of musical authenticity. Within this discourse, progressive rock has already been mentioned. Pop, ska punk and mainstream versions of punk (Blink 182 and 
Green Day and more recently the 'hipster' uses of punk are key examples) have been spoken of in my interviews in terms of vitriolic animosity and were largely judged to be inauthentic genres of punk rock. Such shared hostility in the discourse of punk locates ethical authenticity within this category. The 'hated and related' is of key importance when examining discourse around those bands decried for having 'sold-out'. Perceived inauthentic punk practices, Dave notes below, shift attention and dilute their core ethical values of DiY punk and thus attract righteous hostility, vitriol, scorn, contestation and stereotypical othering. These are generally treated as distasteful, unattractive practices by those members who view them as counter to their core DiY punk aims. Dave presented a rather telling and lengthy example of this in his discussion of what he considers to be the practices that contravene his version of DiY ethics:

You know I can't claim to have a monopoly on punk. I mean it is all over the shop. I find that the history is reinventing stuff and you really notice it as you get older. This is that things get misrepresented and you realise no it wasn't like that: what are you on about you know? You realise that whole strain of stuff that I have been a part of with Flat Earth [records] and anarcho stuff through the nineties, the British, northern hardcore scene and I would say it is not really getting its dues. It's like all these other things have overtaken it. Because we haven't got the big marketing tools and we are not marketing our shit you know like PHD [distribution] or someone's just like swamping. You know, wankers like that: Victory Records you know these are people that I particularly despise. These are people who are just cynical business people. They are just cunts, I haven't got a better word for them. I hate them, I hate what they stand for and they stand for bullshit and capitalism and nothing else. And the fact that people 
like me, who are trying to make a change, trying to fight against this bullshit they are just being swamped by this. But I think as long as I have got a breath in us we will still exist and we will just do our own thing. But my perspective has definitely changed from a big, world changing thing. A big explosive thing like the Crass and the whole anarcho punk thing was big enough to ensnare a lot of people into it and then you have got this very localised, very small underground thing that you are part of cause that is just how it is at the minute. I don't know, DiY does not have to be small but for me it is what I consider worth it. There is so much bullshit out there. I fucking hate everyone [laughter]. I think I'll just quit!

What Dave is castigating above is the biased rewriting of punk history that ignores the activities of northern UK DiY punk rock. He is specifically pointing to what he sees as a rewriting and abandonment of some of the core ethical practices around which he has run his record label for the best part of two decades: his present subcultural reality has been eclipsed by what is perceived as inauthentic action and rewritten history. That corporate marketing strategies of the Ph.D. distribution company or the larger independent record labels such as New York's Victory records have obscured the core reasons for being involved in punk rock meant that the political and ethical dimensions have been equally excised. Dave expressed sharp animosity towards this - 'I hate what they stand for and they stand for bullshit and capitalism and nothing else' - and this in turn increased the pressure for him to continue running his small DiY record label 'as long as I have a breath in us then we will still exist'. A central point here is that through the hated and related (other) the energy is generated for the DIY punk to carry on regardless of the struggles involved in the maintenance and reproduction of the DiY project. 
There is an unwelcome, yet essential, reciprocal relationship between those practices deemed 'un' DiY and the practices described below. Authentic DiY production requires the other wider non-DiY scenes of punk rock as a benchmark in order to both construct and identify itself. This is not applicable in all cases; yet the catalyst for action, in this case DiY, has to be activities that are deemed oppressive, part of the system, major music industry, racist, homophobic, sexist, etc. Without such, the DiY scene loses the anchor of its identity. Yet the reverse can equally be the case: animosity is aimed at what are often deemed politically correct subculture members, from those participants of the non-DiY punk scene who have equal claims on their punk reality. Here this position is articulated by Nobby, a punk in a pub in Bradford who interrupted one of my interviews when he found out I was associated with the anarchist 1 in 12 Club in that city.

the early days, yeah it was set up by the old punks and stuff, yeah, hippies and punks, yeah it were alright. You got all the fucking geeks in there now who you know, don't eat meat, and got a little bit of a line with that now. But, hey, practice what you preach! If that comes into it, practice what you preach for Christ's sake. And they don't know what they've been preaching so they don't even know how to practice it.

Apart from the obvious and interesting evocation of the authentic original category of "the early days' those who run the club 'now' are castigated as 'fucking geeks'. What is interesting here is that there is scorn placed upon the 1 in 12 from those punks who see their version of punk rock tainted by perceived newcomers to the scene. Equally I surmise Club members would respond with equal vitriol. It would be easy here to replace 'hated yet 
related' with the term counter-culture, but the transferability of the present model allows the rhetorical strategies to be unveiled.

The hated yet related is an exceptionally poignant issue that drives the practice of DiY punk: the need to remain autonomous and independent from what is deemed un-DiY, the need to retain control over the cultural production in order that political and artistic statements can be authentically produced without the appropriation of capital for personal gain. The DiY punk subculture is chiefly constituted through its reciprocal 'Other'. It strives to be what the other is not; yet at times they become difficult to distinguish from each other. To the untrained observer, whose interests lie beyond those things punk, such issues may appear trivial or insignificant; yet, to those involved the maintenance and reproduction of the DiY culture becomes an extremely rewarding, taxing and equally frustrating pursuit.

\section{Conclusion}

This article has sought to illuminate and establish a transposable model of 'Distinctions of Authenticity' and its four non-mutually exclusive categories illustrating how authenticity is conveyed and contested in subcultural discourse, gesture and cultural action. My contention in this article is that, while this model is of value as an explanatory tool to map the language, practice of authentication and contestation in subcultures, it has equal value in terms of demonstrating the need for a consistent contextual, wider structural narrative to subcultural studies. Indeed such narrative should endeavour to draw upon a range of methods in order to present an accurately authentic portrayal and discussion of the ongoing construction of punk. As outlined above, the model of 'Distinctions of Authenticity' straddles two possible theoretical cul-de-sacs of subcultural studies. The first was an overarching attempt to 'map' subcultures at the expense of detailed examination of how and in what ways wider ramifications of ethics and social structure are inflected in participant subcultural discourse and practice. While Thornton (1995) and later O'Connor (2008) represent the important and 
key protagonists of this approach, there is much missing in terms of detailed discussion of the everyday complex construction of subcultural authenticity. Additionally, the shifting sands of social structure, hegemony and ideological critique of the CCCS is implicitly present in these accounts in the form of contested micro forms of hegemony revealed in claim and counterclaims of authentic practice. This is of course located within the wider structures of social organization. The fact that this was not raised in later post-subculturalist accounts is problematic and represents the bridge to the second cul-de-sac. Post-subcultural studies, as I noted at the outset, served to address this gap in the construction of authentic subcultural practice, yet with the absence of wider context framed through ideological and ethical drivers of subcultural practice. The broad motif in this model remains descriptive, either concentrating on contestations of sartorial gesture or reductionist accounts of how authenticity is constructed through participant talk: either way a discussion of contrastive ethics is left out in the cold. The methodology of subcultural theory, ethnography, Critical Discourse Analysis and Grounded Theory used to produce Distinctions of Authenticity was generally hostile to both of these approaches, yet in many ways transcends them both by demonstrating how and in what ways wider contextual ethical and ideological discourses shape subcultural authentication contests. This is achieved at the same time as retaining the ethnographic clarity and honesty of remaining focused on what such ethical frameworks mean to those involved in the daily reproduction and authentication of punk subculture.

\section{References}

Althusser, L. (1970), Lenin and Philosophy and Other Essays, London: Verso. 
Antaki, C. (2000), 'Two rhetorical uses of the description "Chat", A Journal of Media and Culture, 3:4. http://journal.media-culture.org.au/0008/uses.php Accessed 15/09/2014

Bennett, A. (2006), 'Punk's not dead: The continuing significance of punk rock for an older generation of fans', Sociology, 40:2, April., pp. 219-235.

Bennett, A. Peterson R, (2004) (eds) Music Scenes: Local, Translocal and Virtual. Nashville: Vanderbilt University Press.

Bennett, T, Martin., G, Mercer, C and Woollacott, J (eds), (1989) Culture, Ideology and Social Process: A Reader, Batsford: The Open University Press.

Bennett, A. and Hodkinson, P. (eds) (2012), Ageing and Youth Cultures: Music, Style and Identity, London: Berg.

Billig, M. (1992), Talking of the Royal Family, London: Routledge.

Blush, S. (2010), American Hardcore: A Tribal History, 2nd ed., Washington: Feral House Press. 
Clarke, J., Hall, S., Jefferson, T. and Roberts, B. ([1970] 1989), 'Subcultures, cultures and class', in T. Bennett, G. Martin, C. Mercer and J. Woollacott (eds), Culture, Ideology and Social Process: A Reader, Batsford: The Open University Press., pp. 53-79.

Cohen, S. (1972), Folk Devils and Moral Panics: The Creation of the Mods and Rockers, Oxford: Martin and Robinson.

Fairclough, N. (1989) Language and Power: Discourse and ideology in the Press. London: Longman.

Glaser, B. (1978), Theoretical Sensitivity, Mill Valley, CA: Sociology Press.

(1992), Emergence vs. Forcing: Basics of Grounded Theory Analysis, California: Sociology Press.

Glaser, B. and Strauss, A. (1967), The Discovery of Grounded Theory, Chicago: Aldine.

Glasper, I. (2006), The Day the Country Died: A History of Anarcho Punk 1980-1984, London: Cherry Red.

(2009), Trapped in a Scene: UK Hardcore 1985-1989, London: Cherry Red. 
Gordon, A. (2014), 'Subcultural entrance practices in UK Punk culture, 1976-2001', in The Subcultures Network (eds), Subcultures, Popular Music and Social Change, Cambridge: Cambridge Scholars Press., pp. 155-174.

(2015), 'They can stuff their punk credentials "Cause it's Them That Take the Cash": 1980s Anarcho Punk ethics from below', in M. Worley and M. Dines (eds), The Anarcho Punk Reader, London: Autonomedia, forthcoming.

Haenfler, R. (2007), Straight Edge: Clean Living Youth, Hardcore Punk and Social Change, New Jersey: Rutgers University Press.

Hall, S. and Jefferson, T. (1976), Resistance through Rituals: Youth Subcultures in Post-War Britain, Birmingham: Unwin Hyman.

Hebdige, D. (1979), Subculture: The Meaning of Style, London: Methuen.

Heresy: John Peel Session 1987, United Kingdom: BBC Radio One.

Heresy: John Peel Session 1988, United Kingdom: BBC Radio One.

Heresy: John Peel Session 1989, United Kingdom: BBC Radio One. 
Hodkinson, P. (2002) Goth: Identity, Style and Subculture, Oxford: Berg.

Jenkins, H. (1992), Textual Poachers, London: Routledge.

Muggleton, D. (1999), Inside Subculture: The Postmodern Meaning of Style, Oxford: Berg.

Muggleton, D. and Weinzierl, R. (eds) (2003), The Post Subcultures Reader, London: Berg.

Napalm Death: John Peel Session 1987, United Kingdom: BBC Radio One.

Napalm Death: John Peel Session 1988, United Kingdom: BBC Radio One.

Napalm Death: John Peel Session 1990, United Kingdom: BBC Radio One.

O’Connor, A. (2002a), Who's Emma: Autonomous Zone and Social Anarchism, Toronto: Confused Editions.

(2002b), 'Local scenes and dangerous crossroads: Punk and Theories of cultural hybridity', Popular Music, 21:2., pp. 235-236. 
(2003), 'Anarcho-Punk: Local Scenes and International Networks', Journal of Anarchist Studies, 11:2., pp. 111-121.

(2008), Punk Record Labels and the Struggle for Autonomy: The Emergence of DiY,

Maryland: Lexington Books.

Sacks, H. (1995), Lectures in Conversation. Volumes 1\&2, New York: John Wiley \& Sons.

Shuker, R. (2011), Wax Tracks and Vinyl Treasures, Aldershot: Ashgate.

Strauss, A. and Corbin, J. (1990), Basics of Qualitative Research Techniques and Procedures for Developing Grounded Theory, London: Sage Publications.

Straw, W. (1991), 'Systems of articulation, logics of change: Communities and scenes in popular music', Cultural Studies, 5:3, pp. 368-88.

The Stupids: John Peel Session 1986,United Kingdom: BBC Radio One.

The Stupids: John Peel Session 1987a, United Kingdom: BBC Radio One.

The Stupids: John Peel Session 1987b, United Kingdom: BBC Radio One.

Thornton, S. (1995), Club Cultures: Music, Media and Subcultural Capital, London: Polity. 
([1995] 1997), 'The social logic of subcultural capital', in K. Gelder and S. Thornton (eds), The Subcultures Reader, London: Routledge., pp. 200 -209.

Ville Karja, A. (2006), ‘A prescribed alternative mainstream: Popular music and canon formation', Popular Music, 25:1., pp. 3-19.

Widdicombe, S. and Wooffitt, R. (1995), The Language of Youth Subcultures: Social Identity in Action, London: Harvester Wheatsheaf.

\section{Contributor details}

Alastair 'Gords' Gordon is Senior Lecturer in Media and Communications at Leicester De Montfort University. His current research is based around genre authenticity and hierarchy across international networks of DiY punk with specific focus on Japan and Europe. He researches in and runs modules on paranormal media. In 2012, Gords co-founded the Punk Scholars Network with Mike Dines and records and tours internationally with his two bands, Geriatric Unit and Endless Grinning Skulls. Gords hates Tories and neo-liberals and collects old socks.

\section{Contact:}

Leicester Media School, De Montfort University, The Gateway, Leicester LE1 9BH, United Kingdom.

E-mail: agordon@dmu.ac.uk 


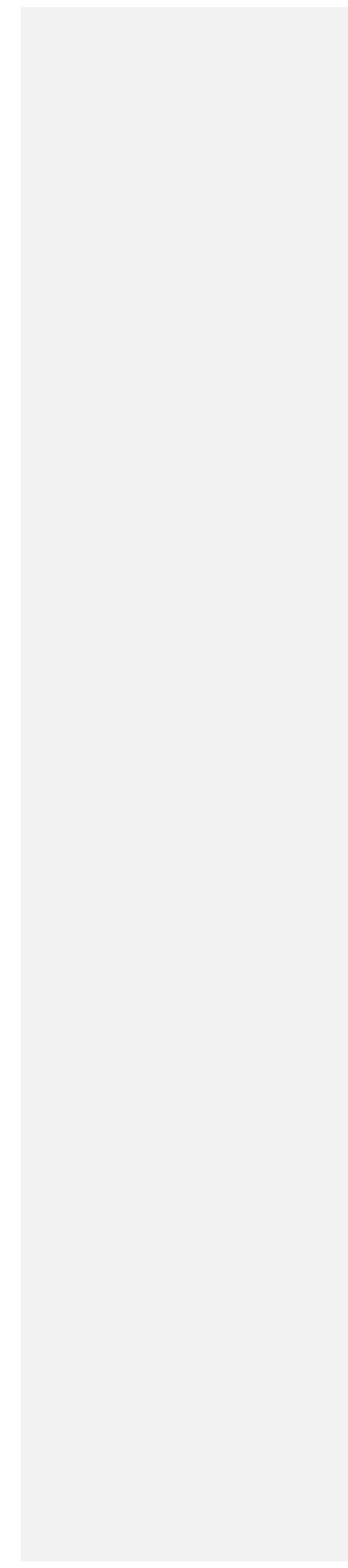

